\title{
Active DNA demethylation: mechanism and role in plant development
}

\author{
Yan $\mathrm{Li}^{1,2} \cdot$ Suresh Kumar $^{3} \cdot$ Weiqiang Qian ${ }^{1}$ (I)
}

Received: 29 June 2017 / Accepted: 5 October 2017 / Published online: 12 October 2017

(C) The Author(s) 2017. This article is an open access publication

\begin{abstract}
Active DNA demethylation (enzymatic removal of methylated cytosine) regulates many plant developmental processes. In Arabidopsis, active DNA demethylation entails the base excision repair pathway initiated by the Repressor of silencing 1/Demeter family of bifunctional DNA glycosylases. In this review, we first present an introduction to the recent advances in our understanding about the mechanisms of active DNA demethylation. We then focus on the role of active DNA demethylation in diverse developmental processes in various plant species, including the regulation of seed development, pollen tube formation, stomatal development, fruit ripening, and nodule development. Finally, we discuss future directions of research in the area of active DNA demethylation.
\end{abstract}

Keywords Demeter - ROS1 - Active DNA demethylation · DNA methylation · Plant development

\section{Introduction}

DNA methylation is an evolutionarily conserved epigenetic mechanism that controls numerous biological processes

Communicated by Tarek Hewezi.

Weiqiang Qian

wqqian@pku.edu.cn

1 State Key Laboratory of Protein and Plant Gene Research, Peking-Tsinghua Center for Life Sciences, School of Life Sciences, Peking University, Beijing 100871, China

2 Center for Plant Biology, School of Life Sciences, Tsinghua University, Beijing 100084, China

3 Division of Biochemistry, ICAR-Indian Agricultural Research Institute, New Delhi 110012, India including gene imprinting, tissue-specific gene expression, inactivation of transposable elements (TEs), paramutation, and stress responses. In plants, DNA methylation occurs in the $\mathrm{CG}, \mathrm{CHG}$ and $\mathrm{CHH}$ contexts (where $\mathrm{H}$ represents A, $\mathrm{C}$, or $\mathrm{T}$ ). The methylation level is dynamically controlled by establishment, maintenance and removal of cytosine methylation (DNA demethylation). The establishment and maintenance of DNA methylation in plants are well understood and have been comprehensively reviewed (Law and Jacobsen 2010; Matzke and Mosher 2014; Movahedi et al. 2015). Here we review DNA demethylation.

DNA demethylation occurs either by passive or active process. Passive DNA demethylation refers to the loss of DNA methylation during DNA replication because of reduction or inactivation of enzymes that contribute to DNA methylation (Zhu 2009). Passive DNA demethylation has been reported during gametophyte development in flowering plants. Male gametophyte generation consists of two- or three-celled pollens that deliver two sperm cells to embryo sac at fertilization. In the pollen, TEs were found to be unexpectedly reactivated only in the vegetative cell, which accompanies the sperm cell but does not provide DNA to the fertilized zygote (Slotkin et al. 2009). In Arabidopsis, reduced expression of the RNA-directed DNA methylation (RdDM) pathway components during male gametogenesis results into passive DNA demethylation in the vegetative cell (Slotkin et al. 2009). Similarly, passive DNA demethylation may also occur in the central cell (the companion cell of the egg that develops into endosperm after fertilization) during female gametophyte development. Transcriptional repression of the maintenance DNA methyltransferase MET1 was found to be associated with genome-wide DNA demethylation in the central cell (Jullien et al. 2008). However, results from a recent study argue against decreased MET1 expression in the central cell (Park et al. 2016), making the 
involvement of passive DNA demethylation in female gametogenesis controversial.

Active DNA demethylation involves the enzymatic removal of methylated cytosine. In plants, this process is initiated by a family of DNA glycosylases including Demeter (DME), Repressor of silencing 1 (ROS1), Demeter-like 2 (DML2), and Demeter-like 3 (DML3). A base excision repair (BER)-dependent mechanism then completes the process (Penterman et al. 2007; Zhu 2009). Active DNA demethylation is not only crucial for genome-wide epigenetic reprogramming but also mediates locus-specific gene activation during plant development (Hsieh et al. 2009). In this paper, we review the recent progress in understanding the mechanisms of active DNA demethylation in plants and highlight the role of this process in plant development.

\section{Mechanisms of active DNA demethylation in plants}

\section{BER-mediated active DNA demethylation}

DME, ROS1, DML2, and DML3 are bifunctional DNA glycosylases involved in BER by hydrolyzing the glycosylic bond between the base and its deoxyribose residue and cleaving the DNA backbone at the abasic site. This removes methylated cytosine irrespective of its sequence context and generate a single-nucleoside gap (Choi et al. 2002; Gong et al. 2002; McCullough et al. 1999; Morales-Ruiz et al. 2006; Ortega-Galisteo et al. 2008). ROS1, DML2, and $D M L 3$ are ubiquitously expressed in vegetative tissues and exhibit partial functional redundancy (Ortega-Galisteo et al. 2008; Penterman et al. 2007; Zhu et al. 2007). However, an Arabidopsis triple mutant of ROS1, DML2, and DML3 ( $r d d$ ) showed DNA hypermethylation (increased level of methylated cytosine) at nearly 9000 loci, which was a considerably higher number than the number of loci specifically targeted by ROS 1 (approximately 5000) (Qian et al. 2012), suggesting that DML2 and DML3 also have unique functions. DME is mainly expressed in the central cell (Choi et al. 2002; Park et al. 2016). Transient $D M E$ expression has also been detected in the vegetative cell (Park et al. 2017; Schoft et al. 2011). In the central and the vegetative cells, DME preferentially targets short, AT-rich and nucleosome-free euchromatic TEs (Ibarra et al. 2012).

DME and ROS 1 catalyze $\beta$ elimination reaction or successive $\beta, \delta$ elimination reaction when cleaving the DNA backbone (Fig. 1). The $\beta$ elimination reaction creates a gap with 3'-phospho- $\alpha, \beta$-unsaturated aldehyde (3'-PUA), while $\beta, \delta$ elimination reaction creates a gap with a 3 '-phosphate terminal (Agius et al. 2006; Lee et al. 2014; Morales-Ruiz et al. 2006). Both 3'-phosphate and 3'-PUA must be converted to $3^{\prime}$-hydroxyl $\left(3^{\prime}-\mathrm{OH}\right)$ so that DNA polymerase

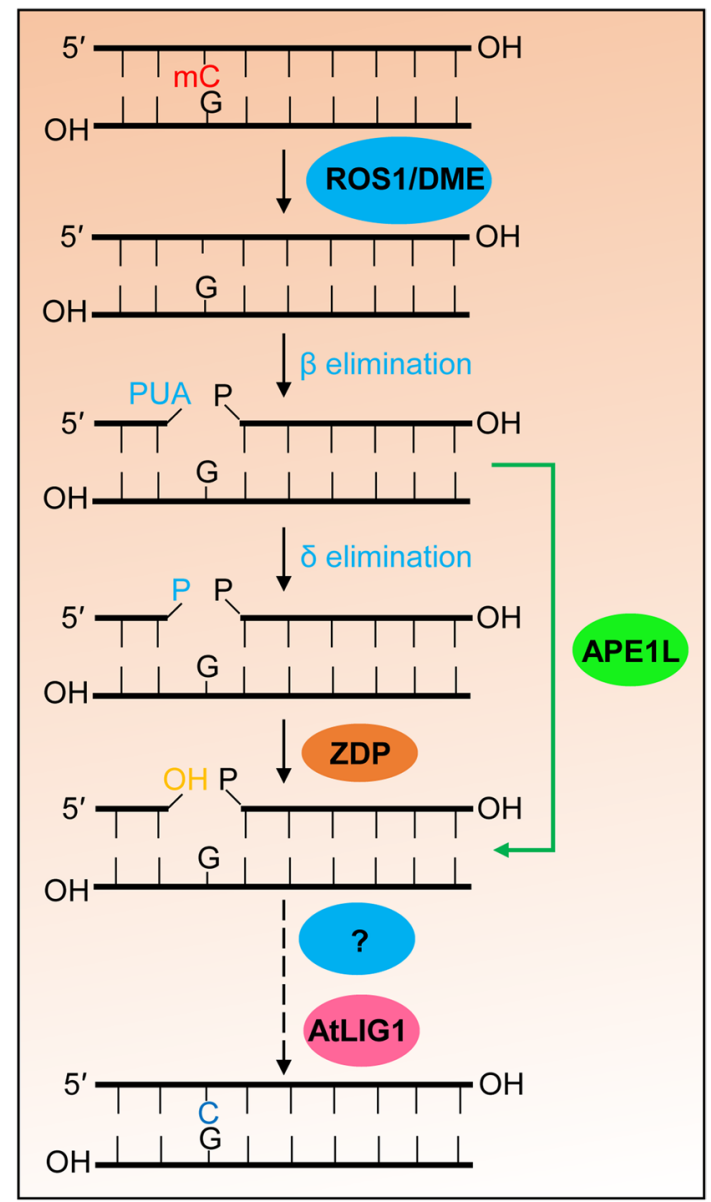

Fig. 1 Base excision repair (BER)-mediated active DNA demethylation in plants. ROS1 and DME are bifunctional DNA glycosylases that remove 5-methylcytosine $(\mathrm{mC})$ and cleave the DNA backbone at abasic site via $\beta$ or $\beta, \delta$ elimination reaction(s), generating a gap with 3'-PUA or 3'-phosphate terminus. 3'-PUA and 3'-phosphate are converted to $3^{\prime}-\mathrm{OH}$ by .APE1L and ZDP, respectively. The gap is then filled with an usual (unmethylated) cytosine by the actions of an unknown DNA polymerase and AtLIG1

and ligase activities can fill in the gap. Zinc finger DNA 3'-phosphoesterase (ZDP) (homologue of human polynucleotide kinase 3'-phosphatase) converts the 3'-phosphate group to a 3'-OH group (Fig. 1) (Jilani et al. 1999; Martinez-Macias et al. 2012). Among three apurinic/apyrimidinic (AP) endonuclease-like proteins APE1L, APE2, and apurinic endonuclease-redox protein in Arabidopsis, APE1L (homologue of human APE1) can potently process 3'-PUA to generate 3'-OH (Fig. 1) (Lee et al. 2014; Li et al. 2015b). ZDP-mediated reaction and APE1L-mediated reaction comprise two branches of the DNA demethylation pathway downstream of ROS1 and DME. Both ZDP and APE1L colocalize and interact with ROS1. ZDP and APE1L dysfunction was reported to cause DNA hypermethylation at approximately 1500 and 3500 endogenous loci, respectively (Li et al. 2015b). ZDP is expressed in both vegetative and 
reproductive tissues (Martinez-Macias et al. 2012), whereas $A P E 1 L$ is mostly expressed in siliques (Lee et al. 2014). Unlike $Z D P$ mutation, which has a slightly greater effect on TE regions, APEIL mutation preferentially causes DNA hypermethylation at genic regions ( $\mathrm{Li}$ et al. 2015b). While the DNA polymerase responsible for active DNA demethylation remains unknown, the DNA ligase, that creates a phosphodiester bond and joins the two ends of DNA strands after filling the gap with an unmethylated cytosine nucleotide, was identified to be AtLIG1 (Fig. 1) (Andreuzza et al. 2010; Li et al. 2015c).

\section{Regulation of DNA glycosylases}

ROS1 transcript level is tightly controlled by the methylation level of an RdDM target sequence (DNA methylation monitoring sequence, MEMS) that lies between ROS1 5' UTR and the promoter TE region (from -40 to -2 bp upstream of the ROS1 transcriptional start site) (Lei et al. 2015) (Fig. 2). When cellular RdDM activities are high or DNA demethylation activities are low, the methylation level of MEMS increases. Increased DNA methylation at MEMS promotes ROSI expression and active DNA demethylation (Lei et al. 2015). By contrast, in RdDM mutants or when DNA demethylation activities are high, the methylation level at MEMS is low and ROS1 expression is suppressed. DNA methylation at MEMS promotes ROS1 expression likely through attracting transcriptional activators (Lei et al. 2015). The methylation-sensitive expression of ROSl helps in maintaining DNA methylation/demethylation homeostasis (Williams et al. 2015). A recent study comprehensively analyzed the necessity and sufficiency of different $D M E$ genomic regions for tissue-specific DME expression (Park et al. 2017). The minimal promoter sequence that can drive $D M E$ expression in the central cell was identified to lie within the $D M E$ transcriptional unit, from +202 to +559 bp downstream of the $D M E$ transcriptional start site (Park et al. 2017). Importantly, the sequences required for the central cell- and vegetative cell-specific $D M E$ expression were narrowed down to a 15-bp region (from +448 to +462 bp) and a 47-bp region (from +416 to $+462 \mathrm{bp}$ ), respectively. The homeodomainleucine zipper family of transcription factors was predicted to bind the overlapping part of these two regions and thereby regulate $D M E$ expression.

ROS1 enzymatic activity was demonstrated to be regulated by the cytosolic iron-sulfur cluster assembly (CIA) pathway components asymmetric leaves $1 / 2$ enhancer 7 (AE7) and METhionine requiring18 (MET18) (Duan et al. 2015; Luo et al. 2012; Wang et al. 2016). MET18 can directly interact with ROS1 in the cytoplasm (Fig. 2). MET18 dysfunction causes compromised ROS1 enzymatic activity and DNA hypermethylation at ROS1 target loci (Duan et al. 2015; Wang et al. 2016). Similar to ROS1, DME is an iron-sulfur cluster binding protein and the iron-sulfur binding motif is crucial for its enzymatic activity (Mok et al. 2010). Although AE7 and MET18 may not regulate DME activity, the other two CIA pathway components, NAR1 and DRE2, regulate the expression of $F W A$, a DME target gene, indicating the involvement of the iron-sulfur cluster assembly in DME-mediated active DNA demethylation (Buzas et al. 2014; Nakamura et al. 2013).

\section{Targeting of the active DNA demethylation machinery}

ROS3 was reported to guide ROS1 to a subset of its target loci by associating with small RNAs (Zheng et al.
Fig. 2 Regulation of ROS1 by the cytosolic iron-sulfur cluster assembly (CIA) pathway and DNA methylation. In the cytoplasm, the CIA pathway component MET18 directly interacts with ROS1, and helps transferring the $\mathrm{Fe}-\mathrm{S}$ cluster to ROS1, which then gets transported into the nucleus to perform active DNA demethylation. The DNA methylation level at the MEMS region in ROS1 promoter is tightly controlled by ROS 1 and RdDM, and higher DNA methylation level promotes $R O S 1$ expression. (+) and (-) symbols represent a positive and negative effect on ROS1 expression, respectively

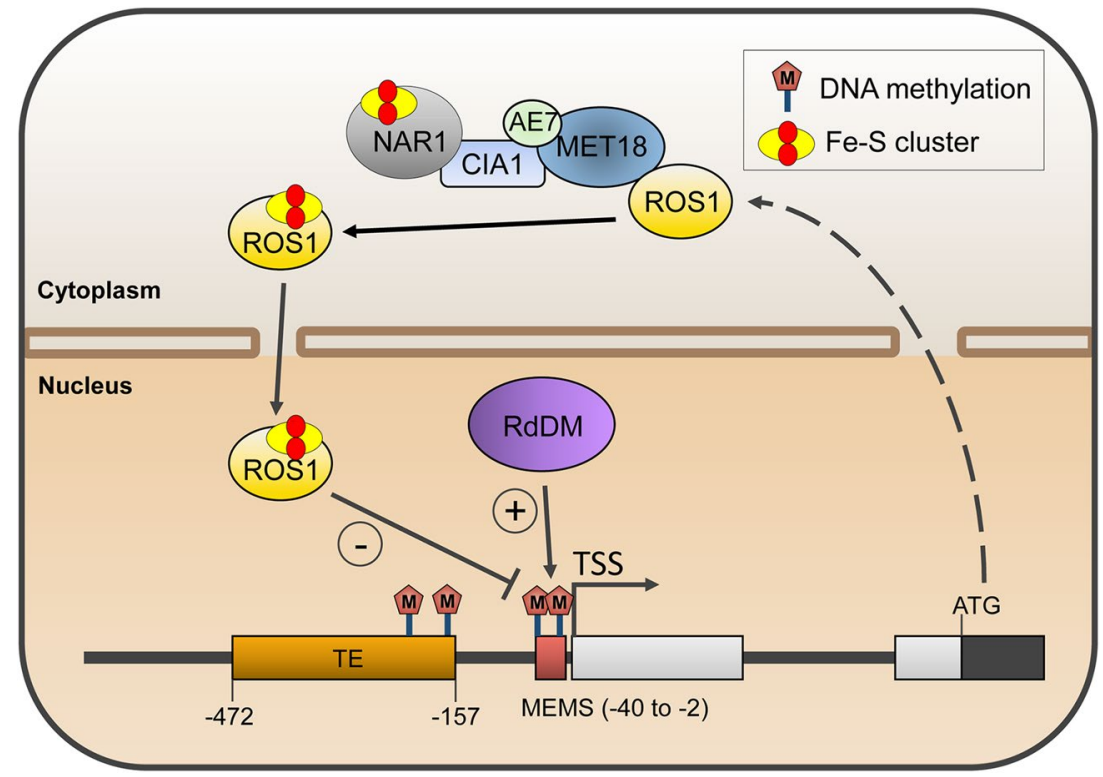


2008). Other studies reported that histone acetyltransferase increased DNA methylation1 (IDM1), also called ROS4, plays a role in ROS1 targeting. IDM1 recognizes loci with high CG methylation but low histone H3K4 dimethylation or trimethylation and adds acetyl marks on H3K18 and H3K23 at these loci. Thus, by creating a permissive chromatin state, IDM1 facilitates ROS1 targeting (Li et al. 2012; Qian et al. 2012). Soon after the discovery of IDM1, IDM2 (also called ROS5), IDM3 (also called increased DNA methylation2like1, IDL1), methyl-CpG-binding protein 7 (MBD7), and Harbinger transposon-derived protein1 (HDP1) and HDP2, which form a complex with IDM1, were identified (Duan et al. 2017; Lang et al. 2015; Li et al. 2015a; Qian et al. 2014; Zhao et al. 2014). MBD7 and HDP2 bind DNA and jointly ensure that IDM1 is targeted to the regions with high CG methylation. IDM2 and IDM3 likely play a role in connecting IDM1 and MBD7, and HDP1 probably mediates the interaction between IDM1 and HDP2. Meanwhile, IDM2 and IDM3 may serve as molecular chaperones that regulate IDM1 enzymatic activity. Taken together, IDM1-mediated ROS1 targeting involves the collective action of all components of the IDM1 histone acetyltransferase complex. Similar to ROS1 targeting, DME targeting may be regulated by multiple factors. Histone $\mathrm{H} 1$ was found to interact with DME and be required for the expression of DME target genes (Rea et al. 2012). SSRP1, a component of the FACT (facilitates chromatin transcription) complex, was also reported to be indispensable for the expression of DME target genes (Ikeda et al. 2011). Because histone H1 and SSRP1 are chromatinbinding proteins, their association with chromatin may control DME targeting. However, the direct evidence for histone H1- and SSRP1-mediated regulation of DME targeting remains to be gathered.

\section{Role of active DNA demethylation in plant development}

The elucidation of mechanisms for active DNA demethylation in plants provides more opportunity to explore the function of active DNA demethylation in gene regulation and plant development. In the last two decades, accumulating evidence indicates that active DNA demethylation regulates diverse biological processes of various plant species (Table 1).

\section{Activation of maternally imprinted genes and regulation of seed development}

The term 'imprinted genes' refers to genes that are preferentially expressed either from maternally or paternally inherited alleles. Since the report of the first imprinted maize $R$ gene, dozens of plant imprinted genes have been identified in the past 20 years (Rodrigues and Zilberman 2015). In Arabidopsis, the well characterized maternally imprinted genes (maternally expressed genes, MEGs) include flowering wageningen (FWA) (Kinoshita et al. 2004), MEDEA (MEA) (Gehring et al. 2006), fertilization independent seed 2 (FIS2) (Jullien et al. 2006), maternally expressed PAB C-terminal (MPC) (Tiwari et al. 2008), AtFH5 (Fitz Gerald et al. 2009), Agamous-like36 (AGL36) (Shirzadi et al. 2011), and NUWA (He et al. 2017). These genes are maintained in a default silenced state owing to DNA methylation and repressive histone modifications. In the central cell of the female gametophyte, the maternal alleles of these MEGs are activated by DME-mediated active DNA demethylation. Although DME expression is confined to the central cell and does not persist in the endosperm, maternal hypomethylation (reduced level of methylated cytosine) and activation of these MEGs are epigenetically maintained in the endosperm (Choi et al. 2002). Mutations in the maternal $D M E$ result in failure of MEG activation and early seed abortion, with endosperm enlarged and embryo growth arrested. Plants homozygous

Table 1 Functions of the known DNA demethylases in plant development

\begin{tabular}{lllll}
\hline Demethylase & Plant & Target gene & Function & References \\
\hline ROS1 & Arabidopsis & EPF2 & Stomatal development & Yamamuro et al. (2014) \\
ROS1, DML2, DML3 & Arabidopsis & APOLO & Auxin-controlled development & Ariel et al. (2014) \\
DME & Arabidopsis & MEA, FIS2, FWA & Gene imprinting and embryo development & Choi et al. (2002) \\
& & & & Gehring et al. (2006) \\
DME & Arabidopsis & unknown & Pollen germination & Schoft et al. (2011) \\
TaDME & Wheat & Gliadins, LMWgs & Gluten abundance & Wen et al. (2012) \\
ROS1a & Rice & unknown & Endosperm and embryo development & Ono et al. (2012) \\
MtDME & Medicago & NCRs & Nodule differentiation & Satge et al. (2016) \\
SIDML2 & Tomato & RIN, NOR, PSY1 & Fruit ripening & Liu et al. (2015) \\
& & & & Lang et al. (2017)
\end{tabular}


for the $D M E$-null mutation do not survive, whereas heterozygous DME/dme- 1 and DME/dme-2 plants exhibit a $50 \%$ seed abortion phenotype due to the maternal effect (Choi et al. 2002). Notably, not only DME, but also proteins acting downstream of DME, including ZDP, APE1L, and DNA ligase I, have been reported to be essential for proper seed development. Although a single $A P E 1 L$ or $Z D P$ mutant does not display any abnormal phenotype, the double mutant of $A P E 1 L$ and $Z D P$ exhibits an embryonic lethal phenotype and the ape $1 l^{+/} z d p^{-/-}$plant, when self-pollinated or pollinated with wild-type pollen, produces approximately $50 \%$ aborted seeds. Endosperms dissected from the aborted seeds (endosperm of the ape $1 l^{-/} z d p^{-/-}$genotype) show DNA hypermethylation of the promoters of selected MEGs, such as FWA and FIS2, and defective activation of FWA and MEA (Li et al. 2015b). Characterization of the mutants for DNA ligase I revealed that DNA ligase I exerts a similar maternal effect on MEG activation and seed development ( $\mathrm{Li}$ et al. 2015c). Besides enzymes directly involved in active DNA demethylation, SSRP1, a component of the FACT complex required for active DNA demethylation in the central cell, also induces a maternal effect on MEG expression and seed development (Ikeda et al. 2011).

Hypomethylation of the maternal genome in the endosperm and activation of MEGs have also been reported in monocots such as rice (Luo et al. 2011; Rodrigues et al. 2013; Zemach et al. 2010) and maize (Waters et al. 2011; Zhang et al. 2011). Thus, active DNA demethylationdependent gene imprinting probably represents a conserved feature of flowering plants. Although the DME homologue is not evident in rice, one of the four ROS1 homologues, ROSI a, appears to be the functional equivalent of Arabidopsis DME (Ono et al. 2012). A mutation in maternal ROSIa resulted into arrested endosperm development and deficient embryo development (Ono et al. 2012). A DME-like gene was recently identified in maize. Notably, its expression level in the endosperm was higher than that observed in the embryo (Wang et al. 2015). Such elevated expression of the DME-like gene could account for hypomethylation of the maternal genome and activation of MEGs in maize endosperm.

\section{Regulation of seed storage protein expression}

Gliadins, low-molecular-weight glutenin subunits (LMWgs), and high-molecular-weight glutenin subunits (HMWgs) are seed storage proteins that accumulate in wheat and barley endosperms. They constitute the primary source of plantbased proteins in our diets. A recent study revealed that wheat $D M E(T a D M E)$ is specifically required for the expression of gliadins and LMWgs, because RNAi suppression of $D M E$ resulted in the reduction or elimination of specific gliadins and LMWgs, but not HMWgs (Wen et al. 2012).
Similarly, demethylation of the promoters of the genes encoding gliadins and LMWgs in barley is necessary for the accumulation of gliadins and LMWgs (Gil-Humanes et al. 2010; Van Herpen et al. 2008), but regulation of HMWgs expression was found to be independent of DNA demethylation (Bethune and Khosla 2012). In light of the difference between the regulation of gliadin and LMWgs expression and that of HMWgs expression in wheat and barley, TaDME and $H v D M E$ suppression is considered a potential strategy for eliminating gliadins and LMWgs that cannot be tolerated by people with celiac disease, while retaining HMWgs that are required for good baking quality (Wen et al. 2012).

\section{Regulation of pollen tube formation}

Arabidopsis seeds carrying a paternal mutant dme allele develop properly, which suggests that DME dysfunction does not lead to defective sperm fertility (Choi et al. 2002). However, DME does function in the male gametophyte because $D M E$ expression in the vegetative cell was found to be required for DNA demethylation of MEA and $F W A$ as well as of the transposon Mula. A DME mutation resulted in impaired vegetative cell germination and pollen tube formation (Schoft et al. 2011). As a result of defective pollen tube formation, self-pollinated DME/dme-1 and DME/dme-2 plants (in the Col-gl background) produce significantly fewer viable heterozygous $D M E / d m e \mathrm{~F} 1$ progenies (approximately $15 \%$ ) than wild-type progenies (Xiao et al. 2003), otherwise the numbers of two types of progenies should have been equal. Notably, the ape $1 l^{+-} z d p^{-/-}$plants also displayed paternal defects such as defective pollen development and germination ( $\mathrm{Li}$ et al. 2015b), further supporting that active DNA demethylation plays a crucial role in male gametogenesis.

\section{Regulation of stomatal development}

Although no obvious developmental phenotypes were observed in the ros 1 and $r d d$ mutants, careful examination of the cellar pattern in the leaf epidermis of these mutants revealed that the ROS1 mutation leads to a 'small-cell-cluster' phenotype (Yamamuro et al. 2014), similar to that seen in the mutants for epidermal patterning factor2 (EPF2), a negative regulator of stomatal development (Hara et al. 2009; Hunt and Gray 2009). The clustered small cells were demonstrated to be stomatal lineage cells. Searching for the methylated region in the EPF2 promoter and comparison of DNA methylation levels in different mutants further revealed that ROS1 is required for demethylation of a TE in the $E P F 2$ promoter and $E P F 2$ expression (Yamamuro et al. 2014). EPF2 negatively regulates speechless ( $S P C H)$, a factor necessary for asymmetric cell division in stomatal development (Jewaria et al. 2013). When ROS1 mutates, EPF2 
expression is reduced and $\mathrm{SPCH}$ expression is depressed. Consequently, stomatal lineage cells are overproduced, with each cell being smaller in size (Yamamuro et al. 2014). These findings suggest that ROS1 mediates lineage-specific DNA demethylation.

\section{Regulation of fruit ripening}

A decrease in the global DNA methylation level in tomato pericarps during ripening suggests the involvement of DNA demethylation in fruit ripening (Teyssier et al. 2008). Passive DNA demethylation unlikely contributes substantially to the DNA demethylation process because limited DNA replication occurs at this developmental stage. Thus, active DNA demethylation may account for the decrease in the DNA methylation levels in tomato pericarps. In support of this, DNA methylation was reported to be specifically removed from 52,095 differentially methylated regions (representing 1\% of the tomato genome) when tomato fruit ripens (Zhong et al. 2013). Among the four putative DNA glycosylase genes [DEMETER-like DNA demethylases (DMLs) of Solanum lycopersicum] SlDML1, SlDML2, $S I D M L 3$, and SIDML4, only SIDML2 was reported to show increased expression during tomato fruit ripening. SIDML2 knockdown using RNAi or SIDML2 knockout using the CRISPR/Cas9 system was reported to be associated with hypermethylation and repression of the selected ripening genes, which resulted in inhibition of fruit ripening (Lang et al. 2017; Liu et al. 2015). Therefore, Liu et al. (2015) and Lang et al. (2017) suggested that SIDML2, a ROS1 orthologue, is the major DNA glycosylase that regulates tomato fruit ripening. Zhong et al. (2013) identified promoters of more than 200 ripening genes, which could be SIDML2 targets, because these promoters show loss of DNA demethylation during tomato ripening; while Lang et al. (2017) identified 605 genes that are hypermethylated and fail to be up-regulated in the sldml2 mutants. Notably, the binding site for RIPENING INHIBITOR (RIN), a MADS-box transcription factor, was found in the promoters of ripening genes, and those promoters in the rin mutant exhibited DNA hypermethylation (Zhong et al. 2013). These findings suggest that SIDML2-mediated active DNA demethylation is somehow facilitated by RIN. Furthermore, the extent of active DNA demethylation was suggested to be dependent on the SIDML2 expression level, which is feedback regulated by the ripening genes (Liu et al. 2015). In wild-type fruits, activation of the ripening genes might stimulate SIDML2 expression, thus leading to thorough DNA demethylation. However, in the fruits of mutants for ripening transcription factors, SIDML2 induction is blocked, thus resulting in limited DNA demethylation. Unexpectedly, SIDML2-mediated active DNA demethylation was reported to be critical for the transcriptional repression of genes that may become useless after fruit ripening (Lang et al. 2017). Thus, active DNA demethylation seems to play a broader role in the regulation of gene expression than was previously recognized.

\section{Regulation of nodule development}

Medicago truncatula is one of the plant species that develop root nodules because of their association with the symbiotic nitrogen-fixing bacteria. A recent study revealed that, among four putative $M$. truncatula DNA glycosylase genes MtDME, MtDML1, MtROS, and MtROSL1, MtDME is strongly induced in the nodule differentiation zone of $M$. truncatula. Knockdown of $M t D M E$ resulted in morphological and functional alterations of the $M$. truncatula nodule, such as reduction in nodule size, decrease in plant and bacterial endoreduplication levels and failure to fix nitrogen (Satge et al. 2016). RNA-seq and whole-genome bisulfite sequencing analyses revealed that MtDME is required for demethylation and activation of TEs and genes essential for nodule development, particularly genes coding for nodule-specific cysteine-rich (NCR) peptides that orchestrate differentiation of symbiotic bacteria into nitrogen-fixing bacteroids in the symbiosome (Satge et al. 2016). However, the counterparts of the maternally imprinted genes MEA, FWA, FIS2, and $M P C$ are not regulated by MtDME in the M. truncatula nodules. Interestingly, TE activation in the differentiation zone was suggested to result in the production of siRNAs that reinforce DNA methylation in the nodule meristem, similar to siRNAs produced in the companion cells of A. thaliana (Calarco et al. 2012; Hsieh et al. 2009; Ibarra et al. 2012).

\section{Concluding remarks and future perspectives}

Recent years have witnessed considerable progress in our understanding of active DNA demethylation. Many of the proteins involved in downstream steps of active DNA demethylation in Arabidopsis have been identified. The factors that regulate targeting or enzymatic activation of DNA glycosylases were discovered, and active DNA demethylation was established to play a crucial role in a broad range of developmental processes in several plant species. However, many areas remain unexplored. First, the mechanism(s) for recruitment of DNA glycosylases to specific loci remains unclear. The IDM1 complex only directs ROS1 targeting to a subset of its target loci. Unlike dysfunction of ROS1 or DME, dysfunction of the IDM1 complex components does not give rise to any obvious phenotype (Qian et al. 2012). Thus, there must be unidentified factors that also contribute to ROS1 or DME targeting. Second, few factors that regulate active DNA demethylation activities during specific developmental events have been identified. For instance, auxin has been shown to trigger active DNA demethylation at the APOLO (AUXIN REGULATED PROMOTER 
LOOP RNA) locus in Arabidopsis (Ariel et al. 2014). However, factors that connect auxin to active DNA demethylation at the $A P O L O$ locus remain unknown. Moreover, it is still unclear that how SIDML2 and MtDME are specifically induced during fruit ripening and nodule development, respectively. Identification of key components involved in these processes, for instance, specific transcription factors, will deepen our understanding of the role of active DNA demethylation in these development events. Third, so far, the developmental processes that are known to be regulated by active DNA demethylation are limited. It will be interesting to investigate the role of active DNA demethylation in other important developmental processes, such as flowering, sexual reproduction, seed germination and programmed cell death. Now the role of active DNA demethylation in different biological processes in different species can be assessed by applying the CRISPR/Cas9 technology to genes involved in the active DNA demethylation pathway. Finally, controlling gene expression by manipulating DNA methylation and demethylation status of specific sites is a direction for future research. However, site-specific targeting of factors that facilitate active DNA demethylation using enzymatically inactive Cas9 (dead Cas9, dCas9) fusion has only been tested in mammalian cells (Xu et al. 2016). Development and optimization of RNA-guided dCas9 demethylation technology in plants would help understanding the mechanistic aspects of DNA methylation or demethylation, and the practical applicability of epigenetic manipulation in plants. The genome-editing technologies are improving rapidly, and sooner might reach to a point that may enable plant epigenome engineering to be a success. The coming years are likely to realize improved opportunities for comprehensive functional interrogation of epigenetic marks and engineering crop epigenomes towards stable improvement of agriculturally important traits (Springer and Schmitz 2017; Stricker et al. 2017).

Author contribution statement YL, SK, and WQ designed and wrote the review.

\begin{abstract}
Acknowledgements We thank Y. N. Liu for technical assistance. The authors also appreciate the constructive feedback from reviewers that helped to improve the article. This work was supported by the National Natural Science Foundation of China (31522005) and Thousand Youth Talents Program to W.Q.
\end{abstract}

\section{Compliance with ethical standards}

Conflict of interest The authors declare that they have no conflict of interest.

Open Access This article is distributed under the terms of the Creative Commons Attribution 4.0 International License (http://creativecommons.org/licenses/by/4.0/), which permits unrestricted use, distribution, and reproduction in any medium, provided you give appropriate credit to the original author(s) and the source, provide a link to the Creative Commons license, and indicate if changes were made.

\section{References}

Agius F, Kapoor A, Zhu JK (2006) Role of the Arabidopsis DNA glycosylase/lyase ROS1 in active DNA demethylation. Proc Natl Acad Sci USA 103:11796-11801

Andreuzza S, Li J, Guitton AE, Faure JE, Casanova S, Park JS et al (2010) DNA LIGASE I exerts a maternal effect on seed development in Arabidopsis thaliana. Development 137:73-81

Ariel F, Jegu T, Latrasse D, Romero-Barrios N, Christ A, Benhamed $\mathrm{M}$ et al (2014) Noncoding transcription by alternative RNA polymerases dynamically regulates an auxin-driven chromatin loop. Mol Cell 55:383-396

Bethune MT, Khosla C (2012) Oral enzyme therapy for celiac sprue. Methods Enzymol 502:241-271

Buzas DM, Nakamura M, Kinoshita T (2014) Epigenetic role for the conserved $\mathrm{Fe}-\mathrm{S}$ cluster biogenesis protein AtDRE2 in Arabidopsis thaliana. Proc Natl Acad Sci USA 111:13565-13570

Calarco JP, Borges F, Donoghue MT, Van Ex F, Jullien PE, Lopes T et al (2012) Reprogramming of DNA methylation in pollen guides epigenetic inheritance via small RNA. Cell 151:194-205

Choi Y, Gehring M, Johnson L, Hannon M, Harada JJ, Goldberg RB et al (2002) DEMETER, a DNA glycosylase domain protein, is required for endosperm gene imprinting and seed viability in Arabidopsis. Cell 110:33-42

Duan CG, Wang X, Tang K, Zhang H, Mangrauthia SK, Lei M et al (2015) MET18 connects the cytosolic iron-sulfur cluster assembly pathway to active DNA demethylation in Arabidopsis. PLoS Genet 11:e1005559

Duan CG, Wang X, Xie S, Pan L, Miki D, Tang K et al (2017) A pair of transposon-derived proteins function in a histone acetyltransferase complex for active DNA demethylation. Cell Res 27:226-240

Fitz Gerald JN, Hui PS, Berger F (2009) Polycomb group-dependent imprinting of the actin regulator AtFH5 regulates morphogenesis in Arabidopsis thaliana. Development 136:3399-3404

Gehring M, Huh JH, Hsieh TF, Penterman J, Choi Y, Harada JJ et al (2006) DEMETER DNA glycosylase establishes MEDEA polycomb gene self-imprinting by allele-specific demethylation. Cell 124:495-506

Gil-Humanes J, Piston F, Tollefsen S, Sollid LM, Barro F (2010) Effective shutdown in the expression of celiac disease-related wheat gliadin T-cell epitopes by RNA interference. Proc Natl Acad Sci USA 107:17023-17028

Gong Z, Morales-Ruiz T, Ariza RR, Roldan-Arjona T, David L, Zhu JK (2002) ROS1, a repressor of transcriptional gene silencing in Arabidopsis, encodes a DNA glycosylase/lyase. Cell 111:803-814

Hara K, Yokoo T, Kajita R, Onishi T, Yahata S, Peterson KM et al (2009) Epidermal cell density is autoregulated via a secretory peptide, EPIDERMAL PATTERNING FACTOR 2 in Arabidopsis leaves. Plant Cell Physiol 50:1019-1031

He S, Sun Y, Yang Q, Zhang X, Huang Q, Zhao P et al (2017) A novel imprinted gene $N U W A$ controls mitochondrial function in early seed development in Arabidopsis. PLoS Genet 13:e1006553

Hsieh TF, Ibarra CA, Silva P, Zemach A, Eshed-Williams L, Fischer RL et al (2009) Genome-wide demethylation of Arabidopsis endosperm. Science 324:1451-1454

Hunt L, Gray JE (2009) The signaling peptide EPF2 controls asymmetric cell divisions during stomatal development. Curr Biol 19:864-869 
Ibarra CA, Feng X, Schoft VK, Hsieh TF, Uzawa R, Rodrigues JA et al (2012) Active DNA demethylation in plant companion cells reinforces transposon methylation in gametes. Science 337:1360-1364

Ikeda Y, Kinoshita Y, Susaki D, Ikeda Y, Iwano M, Takayama S et al (2011) HMG domain containing SSRP1 is required for DNA demethylation and genomic imprinting in Arabidopsis. Dev Cell 21:589-596

Jewaria PK, Hara T, Tanaka H, Kondo T, Betsuyaku S, Sawa S et al (2013) Differential effects of the peptides Stomagen, EPF1 and EPF2 on activation of MAP kinase MPK6 and the SPCH protein level. Plant Cell Physiol 54:1253-1262

Jilani A, Ramotar D, Slack C, Ong C, Yang XM, Scherer SW et al (1999) Molecular cloning of the human gene, PNKP, encoding a polynucleotide kinase 3 '-phosphatase and evidence for its role in repair of DNA strand breaks caused by oxidative damage. J Biol Chem 274:24176-24186

Jullien PE, Kinoshita T, Ohad N, Berger F (2006) Maintenance of DNA methylation during the Arabidopsis life cycle is essential for parental imprinting. Plant Cell 18:1360-1372

Jullien PE, Mosquna A, Ingouff M, Sakata T, Ohad N, Berger F (2008) Retinoblastoma and its binding partner MSI1 control imprinting in Arabidopsis. PLoS Biol 6:e194

Kinoshita T, Miura A, Choi Y, Kinoshita Y, Cao X, Jacobsen SE et al (2004) One-way control of FWA imprinting in Arabidopsis endosperm by DNA methylation. Science 303:521-523

Lang Z, Lei M, Wang X, Tang K, Miki D, Zhang H et al (2015) The methyl-CpG-binding protein MBD7 facilitates active DNA demethylation to limit DNA hyper-methylation and transcriptional gene silencing. Mol Cell 57:971-983

Lang Z, Wang Y, Tang K, Tang D, Datsenka T, Cheng J et al (2017) Critical roles of DNA demethylation in the activation of ripening-induced genes and inhibition of ripening-repressed genes in tomato fruit. Proc Natl Acad Sci USA 114:E4511-E4519

Law JA, Jacobsen SE (2010) Establishing, maintaining and modifying DNA methylation patterns in plants and animals. Nat Rev Genet 11:204-220

Lee J, Jang H, Shin H, Choi WL, Mok YG, Huh JH (2014) AP endonucleases process 5-methylcytosine excision intermediates during active DNA demethylation in Arabidopsis. Nucleic Acids Res 42:11408-11418

Lei M, Zhang H, Julian R, Tang K, Xie S, Zhu JK (2015) Regulatory link between DNA methylation and active demethylation in Arabidopsis. Proc Natl Acad Sci USA 112:3553-3557

Li X, Qian W, Zhao Y, Wang C, Shen J, Zhu JK et al (2012) Antisilencing role of the RNA-directed DNA methylation pathway and a histone acetyltransferase in Arabidopsis. Proc Natl Acad Sci USA 109:11425-11430

Li Q, Wang X, Sun H, Zeng J, Cao Z, Li Y et al (2015a) Regulation of active DNA demethylation by a methyl-CpG-binding domain protein in Arabidopsis thaliana. PLoS Genet 11:e1005210

Li Y, Cordoba-Canero D, Qian W, Zhu X, Tang K, Zhang H et al (2015b) An AP endonuclease functions in active DNA demethylation and gene imprinting in Arabidopsis. PLoS Genet 11:e1004905

Li Y, Duan CG, Zhu X, Qian W, Zhu JK (2015c) A DNA ligase required for active DNA demethylation and genomic imprinting in Arabidopsis. Cell Res 25:757-760

Liu R, How-Kit A, Stammitti L, Teyssier E, Rolin D, MortainBertrand A et al (2015) A DEMETER-like DNA demethylase governs tomato fruit ripening. Proc Natl Acad Sci USA 112:10804-10809

Luo M, Taylor JM, Spriggs A, Zhang H, Wu X, Russell S et al (2011) A genome-wide survey of imprinted genes in rice seeds reveals imprinting primarily occurs in the endosperm. PLoS Genet 7:e1002125
Luo D, Bernard DG, Balk J, Hai H, Cui X (2012) The DUF59 family gene AE7 acts in the cytosolic iron-sulfur cluster assembly pathway to maintain nuclear genome integrity in Arabidopsis. Plant Cell 24:4135-4148

Martinez-Macias MI, Qian W, Miki D, Pontes O, Liu Y, Tang K et al (2012) A DNA 3' phosphatase functions in active DNA demethylation in Arabidopsis. Mol Cell 45:357-370

Matzke MA, Mosher RA (2014) RNA-directed DNA methylation: an epigenetic pathway of increasing complexity. Nat Rev Genet 15:394-408

McCullough AK, Dodson ML, Lloyd RS (1999) Initiation of base excision repair: glycosylase mechanisms and structures. Annu Rev Biochem 68:255-285

Mok YG, Uzawa R, Lee J, Weiner GM, Eichman BF, Fischer RL et al (2010) Domain structure of the DEMETER 5-methylcytosine DNA glycosylase. Proc Natl Acad Sci USA 107:19225-19230

Morales-Ruiz T, Ortega-Galisteo AP, Ponferrada-Marin MI, MartinezMacias MI, Ariza RR, Roldan-Arjona T (2006) DEMETER and REPRESSOR OF SILENCING 1 encode 5-methylcytosine DNA glycosylases. Proc Natl Acad Sci USA 103:6853-6858

Movahedi A, Sun W, Zhang J, Wu X, Mousavi M, Mohammadi K et al (2015) RNA-directed DNA methylation in plants. Plant Cell Rep 34:1857-1862

Nakamura M, Buzas DM, Kato A, Fujita M, Kurata N, Kinoshita T (2013) The role of Arabidopsis thaliana NAR1, a cytosolic iron-sulfur cluster assembly component, in gametophytic gene expression and oxidative stress responses in vegetative tissue. New Phytol 199:925-935

Ono A, Yamaguchi K, Fukada-Tanaka S, Terada R, Mitsui T, Iida S (2012) A null mutation of ROS1a for DNA demethylation in rice is not transmittable to progeny. Plant J 71:564-574

Ortega-Galisteo AP, Morales-Ruiz T, Ariza RR, Roldan-Arjona T (2008) Arabidopsis DEMETER-LIKE proteins DML2 and DML3 are required for appropriate distribution of DNA methylation marks. Plant Mol Biol 67:671-681

Park K, Kim MY, Vickers M, Park JS, Hyun Y, Okamoto T et al (2016) DNA demethylation is initiated in the central cells of Arabidopsis and rice. Proc Natl Acad Sci USA 113:15138-15143

Park JS, Frost JM, Park K, Ohr H, Park GT, Kim S et al (2017) Control of DEMETER DNA demethylase gene transcription in male and female gamete companion cells in Arabidopsis thaliana. Proc Natl Acad Sci USA 114:2078-2083

Penterman J, Zilberman D, Huh JH, Ballinger T, Henikoff S, Fischer RL (2007) DNA demethylation in the Arabidopsis genome. Proc Natl Acad Sci USA 104:6752-6757

Qian W, Miki D, Zhang H, Liu Y, Zhang X, Tang K et al (2012) A histone acetyltransferase regulates active DNA demethylation in Arabidopsis. Science 336:1445-1448

Qian W, Miki D, Lei M, Zhu X, Zhang H, Liu Y et al (2014) Regulation of active DNA demethylation by an $\alpha$-crystallin domain protein in Arabidopsis. Mol Cell 55:361-371

Rea M, Zheng W, Chen M, Braud C, Bhangu D, Rognan TN et al (2012) Histone H1 affects gene imprinting and DNA methylation in Arabidopsis. Plant J 71:776-786

Rodrigues JA, Zilberman D (2015) Evolution and function of genomic imprinting in plants. Genes Dev 29:2517-2531

Rodrigues JA, Ruan R, Nishimura T, Sharma MK, Sharma R, Ronald PC et al (2013) Imprinted expression of genes and small RNA is associated with localized hypomethylation of the maternal genome in rice endosperm. Proc Natl Acad Sci USA 110:7934-7939

Satge C, Moreau S, Sallet E, Lefort G, Auriac MC, Rembliere C et al (2016) Reprogramming of DNA methylation is critical for nodule development in Medicago truncatula. Nat Plants 2:16166

Schoft VK, Chumak N, Choi Y, Hannon M, Garcia-Aguilar M, Machlicova A et al (2011) Function of the DEMETER DNA glycosylase 
in the Arabidopsis thaliana male gametophyte. Proc Natl Acad Sci USA 108:8042-8047

Shirzadi R, Andersen ED, Bjerkan KN, Gloeckle BM, Heese M, Ungru A et al (2011) Genome-wide transcript profiling of endosperm without paternal contribution identifies parent-of-origin-dependent regulation of AGAMOUS-LIKE36. PLoS Genet 7:e1001303

Slotkin RK, Vaughn M, Borges F, Tanurdzic M, Becker JD, Feijo JA et al (2009) Epigenetic reprogramming and small RNA silencing of transposable elements in pollen. Cell 136:461-472

Springer NM, Schmitz RJ (2017) Exploiting induced and natural epigenetic variation for crop improvement. Nat Rev Genet 18:563-575

Stricker SH, Koferle A, Beck S (2017) From profiles to function in epigenomics. Nat Rev Genet 18:51-66

Teyssier E, Bernacchia G, Maury S, How Kit A, Stammitti-Bert L, Rolin D et al (2008) Tissue dependent variations of DNA methylation and endoreduplication levels during tomato fruit development and ripening. Planta 228:391-399

Tiwari S, Schulz R, Ikeda Y, Dytham L, Bravo J, Mathers L et al (2008) MATERNALLY EXPRESSED PAB C-TERMINAL, a novel imprinted gene in Arabidopsis, encodes the conserved C-terminal domain of polyadenylate binding proteins. Plant Cell 20:2387-2398

Van Herpen TW, Riley M, Sparks C, Jones HD, Gritsch C, Dekking EH et al (2008) Detailed analysis of the expression of an alpha-gliadin promoter and the deposition of alpha-gliadin protein during wheat grain development. Ann Bot 102:331-342

Wang P, Xia H, Zhang Y, Zhao S, Zhao C, Hou L et al (2015) Genomewide high-resolution mapping of DNA methylation identifies epigenetic variation across embryo and endosperm in maize. BMC Genom 16:21

Wang X, Li Q, Yuan W, Cao Z, Qi B, Kumar S et al (2016) The cytosolic Fe-S cluster assembly component MET18 is required for the full enzymatic activity of ROS1 in active DNA demethylation. Sci Rep 6:26443

Waters AJ, Makarevitch I, Eichten SR, Swanson-Wagner RA, Yeh CT, Xu W et al (2011) Parent-of-origin effects on gene expression and DNA methylation in the maize endosperm. Plant Cell 23:4221-4233

Wen S, Wen N, Pang J, Langen G, Brew-Appiah RA, Mejias JH et al (2012) Structural genes of wheat and barley 5-methylcytosine
DNA glycosylases and their potential applications for human health. Proc Natl Acad Sci USA 109:20543-20548

Williams BP, Pignatta D, Henikoff S, Gehring M (2015) Methylationsensitive expression of a DNA demethylase gene serves as an epigenetic rheostat. PLoS Genet 11:e1005142

Xiao W, Gehring M, Choi Y, Margossian L, Pu H, Harada JJ et al (2003) Imprinting of the MEA Polycomb gene is controlled by antagonism between MET1 methyltransferase and DME glycosylase. Dev Cell 5:891-901

Xu X, Tao Y, Gao X, Zhang L, Li X, Zou W et al (2016) A CRISPRbased approach for targeted DNA demethylation. Cell Discov 2:16009

Yamamuro C, Miki D, Zheng Z, Ma J, Wang J, Yang Z et al (2014) Overproduction of stomatal lineage cells in Arabidopsis mutants defective in active DNA demethylation. Nat Commun 5:4062

Zemach A, Kim MY, Silva P, Rodrigues JA, Dotson B, Brooks MD et al (2010) Local DNA hypomethylation activates genes in rice endosperm. Proc Natl Acad Sci USA 107:18729-18734

Zhang M, Zhao H, Xie S, Chen J, Xu Y, Wang K et al (2011) Extensive, clustered parental imprinting of protein-coding and noncoding RNAs in developing maize endosperm. Proc Natl Acad Sci USA 108:20042-20047

Zhao Y, Xie S, Li X, Wang C, Chen Z, Lai J et al (2014) REPRESSOR OF SILENCING5 encodes a member of the small heat shock protein family and is required for DNA demethylation in Arabidopsis. Plant Cell 26:2660-2675

Zheng X, Pontes O, Zhu J, Miki D, Zhang F, Li WX et al (2008) ROS3 is an RNA-binding protein required for DNA demethylation in Arabidopsis. Nature 455:1259-1262

Zhong S, Fei Z, Chen YR, Zheng Y, Huang M, Vrebalov J et al (2013) Single-base resolution methylomes of tomato fruit development reveal epigenome modifications associated with ripening. Nat Biotechnol 31:154-159

Zhu JK (2009) Active DNA demethylation mediated by DNA glycosylases. Annu Rev Genet 43:143-166

Zhu J, Kapoor A, Sridhar VV, Agius F, Zhu JK (2007) The DNA glycosylase/lyase ROS1 functions in pruning DNA methylation patterns in Arabidopsis. Curr Biol 17:54-59 